\author{
F. Calcinaro - S. Dionisi - M. Marinaro $\cdot$ P. Candeloro $\cdot$ V. Bonato $\cdot$ S. Marzotti $\cdot$ \\ R. B. Corneli - E. Ferretti - A. Gulino - F. Grasso - C. De Simone - U. Di Mario • \\ A. Falorni $\cdot$ M. Boirivant $\cdot$ F. Dotta
}

\title{
Oral probiotic administration induces interleukin-10 production and prevents spontaneous autoimmune diabetes in the non-obese diabetic mouse
}

Received: 6 December 2004 / Accepted: 18 April 2005 / Published online: 29 June 2005

(C) Springer-Verlag 2005

\begin{abstract}
Aims/hypothesis: Recent observations suggest the involvement of the gastrointestinal tract in the pathogenesis of islet autoimmunity. Thus, the modulation of gut-associated lymphoid tissue may represent a means to affect the natural history of the disease. Oral administra-
\end{abstract}

F. Calcinaro $\cdot$ P. Candeloro $\cdot$ S. Marzotti $\cdot$ A. Falorni Department of Internal Medicine, University of Perugia, Perugia, Italy

S. Dionisi · V. Bonato · U. Di Mario · F. Dotta Department of Clinical Sciences,

University of Rome La Sapienza,

Rome, Italy

M. Marinaro · F. Grasso · M. Boirivant $(\bowtie)$

Immune-mediated Diseases Section, Department of Infectious,

Parasitic and Immune-mediated Diseases,

Istituto Superiore di Sanità,

Viale Regina Elena, 299,

00161 Rome, Italy

e-mail: monboir@iss.it

Tel.: +39-06-49902976

Fax: +39-06-49902709

R. B. Corneli

Department of Experimental Medicine

and Biochemical Sciences, University of Perugia,

Perugia, Italy

E. Ferretti · A. Gulino

Department of Experimental Medicine and Pathology,

University of Rome La Sapienza,

Rome, Italy

C. De Simone

Department of Experimental Medicine,

University of L'Aquila,

L'Aquila, Italy

F. Dotta

Diabetes Unit, Department of Internal Medicine,

Endocrine and Metabolic Sciences and Biochemistry,

University of Siena,

Siena, Italy tion of probiotic bacteria can modulate local and systemic immune responses; consequently, we investigated the effects of oral administration of the probiotic compound VSL\#3 on the occurrence of diabetes in non-obese diabetic (NOD) mice. Methods: VSL\#3 was administered to female NOD mice three times a week starting from 4 weeks of age. A control group received PBS. Whole blood glucose was measured twice a week. IFN- $\gamma$ and IL-10 production/expression was evaluated by ELISA in culture supernatants of mononuclear cells isolated from Peyer's patches and the spleen, and by real-time PCR in the pancreas. Insulitis was characterised by immunohistochemistry and histomorphometric studies. Results: Early oral administration of VSL\#3 prevented diabetes development in NOD mice. Protected mice showed reduced insulitis and a decreased rate of beta cell destruction. Prevention was associated with an increased production of IL-10 from Peyer's patches and the spleen and with increased IL-10 expression in the pancreas, where IL-10-positive islet-infiltrating mononuclear cells were detected. The protective effect of VSL\#3 was transferable to irradiated mice receiving diabetogenic cells and splenocytes from VSL\#3-treated mice. Conclusions/interpretation: Orally administered VSL\#3 prevents autoimmune diabetes and induces immunomodulation by a reduction in insulitis severity. Our results provide a sound rationale for future clinical trials of the primary prevention of type 1 diabetes by oral VSL\#3 administration.

Keywords Autoimmunity · Gut-associated lymphoid tissue - IL-10 - Immunomodulation · NOD mouse · Probiotics $\cdot$ Type 1 diabetes

Abbreviations HBSS: Hanks' balanced salt solution H-E: haematoxylin-eosin - GALT: gut-associated lymphoid tissue - MAdCAM-1: mucosal addressin cell adhesion molecule $\cdot$ MNCs: mononuclear cells $\cdot$ NOD: non-obese diabetic $\cdot$ PPs: Peyer's patches 


\section{Introduction}

Type 1 diabetes mellitus is an organ-specific autoimmune disease that develops in genetically predisposed individuals. Several attempts have been made to identify environmental trigger factors, the role of beta cell antigens in inducing and maintaining the autoimmune response, and the nature of the pathogenic immune mechanisms involved $[1,2]$. Due to the chronic complications of the disease, the development of strategies aiming to delay or prevent autoimmune beta cell loss would result in a major benefit to public health. As $90 \%$ of type 1 diabetes patients have no affected relatives, primary prevention in the general population is the ultimate goal. This can only be achieved via a strategy that combines efficacy, safety, specificity of action, low cost and adequate compliance by children.

The non-obese diabetic (NOD) mouse develops a spontaneous form of autoimmune diabetes that mimics many features of the human disease, thus representing a model for investigating possible therapeutic approaches $[3,4]$.

Recent observations in humans and animal models have drawn attention to a possible involvement of the gastrointestinal tract in the pathogenesis of autoimmune diabetes, mainly as a possible way-in site of putative trigger factors. This is in light of the reported association of some dietary antigens, such as cows' milk proteins, gliadin and other cereal components, and of enteric infections with the disease [5-9]. A link between gut-associated lymphoid tissue (GALT) and autoimmune diabetes has already been shown in animal models; indeed, mesenteric lymphocytes from 3-week-old NOD mice had a high diabetogenic potential [10], and diet manipulations were able to modify disease incidence and the pattern of islet-infiltrating lymphocytes and cytokine production [11]. Thus, the modulation of GALT may represent a means to affect the natural history of autoimmune diabetes.

Probiotics are defined as 'mono- or mixed cultures of live micro-organisms which, when applied to animal or man, beneficially affect the host by improving the properties of the indigenous microflora' [12]. Administration of probiotics in humans and animal models has been shown to be beneficial in the treatment and prevention of intestinal infections and to reduce mucosal inflammation [13-19]. This effect probably results from the ability of probiotics to adhere to mucosal surfaces and inhibit the attachment of other pathogenic bacteria, to secrete factors that enhance barrier integrity, and to modulate cells of the immune system $[18,20-24]$. Their ability to deviate tissue cytokine secretion from a pro-inflammatory to an anti-inflammatory profile has been specifically described [18, 19, 23].

It has been reported that oral administration of heatkilled Lactobacillus casei to NOD mice reduces the incidence of diabetes, but the mechanism underlying this finding has not been elucidated [25].

The aim of this study was to investigate the effect of oral administration of VSL\#3, a clinically safe mixture of different strains of viable lyophilised probiotic bacteria, on the occurrence of spontaneous autoimmune diabetes in NOD mice.

\section{Materials and methods}

Mice Four-week-old female NOD mice were obtained from Charles River Laboratories (Calco, Milan, Italy) and housed under specific pathogen-free conditions in the animal facility at the University of Perugia; these mice were used for all experiments. Animals had free access to water and food. All studies were approved by the Animal Care and Use Committee of the University of Perugia and by the Italian Ministry of Health.

Probiotic preparation VSL\#3 (VSL Pharmaceuticals, Ft Lauderdale, FL, USA) is a probiotic compound containing $3 \times 10^{11} / \mathrm{g}$ viable lyophilised bacteria, including bifidobacteria (B. longum, B. infantis and B. breve), lactobacilli (L. acidophilus, L. casei, L. delbrueckii subsp. L. bulgaricus and L. plantarum) and Streptococcus salivarius subsp. thermophilus.

Experimental design The study was designed as summarised in Fig. 1. To evaluate the effect of VSL\#3 administration on the onset of diabetes, NOD mice were randomly subdivided into two groups (Fig. 1a). In group 1, VSL\#3 (3 mg/mouse, re-suspended in $100 \mu \mathrm{l}$ PBS) was administered orally by gavage three times a week from 4 to 32 weeks of age. In group 2, an equal volume of PBS was administered orally by gavage three times a week from 4 to 32 weeks of age. Mice were monitored for the appearance of clinical signs of diabetes and were killed at disease occurrence.

At 32 weeks of age, the mice of group 1 (VSL\#3treated) that remained diabetes free $(n=15)$ were divided into three subgroups (Fig. 1b). Subgroup 1a continued VSL\#3 treatment under the same conditions. Subgroup 1b stopped VSL\#3 treatment and started PBS administration as for group 2. Subgroup 1c continued VSL\#3 treatment and received a single i.p. cyclophosphamide injection (250 $\mathrm{mg} / \mathrm{kg}$ body weight).

This study was stopped at 280 days of age and all remaining non-diabetic mice from all groups were killed for the evaluation of insulitis.

In a parallel study, containing a separate series of VSL\#3or PBS-treated animals, mice were killed at 8 and 12 weeks of age (after 4 and 8 weeks of treatment) respectively. The pancreas, the spleen and Peyer's patches (PPs) were collected from each mouse for the evaluation of insulitis and cytokine production.

To evaluate the effect of VSL\#3 administration later in the disease process, 36 additional female NOD mice, housed as previously described, were randomly subdivided into two groups. In group $1(n=18), \mathrm{VSL} \# 3$ (3 mg/mouse, re-suspended in $100 \mu \mathrm{l}$ PBS) was administered orally by gavage three times per week from 10 to 32 weeks of age. In group 2 (control; $n=18$ ), an equal volume of PBS was administered orally by gavage three times per week from 10 to 32 weeks of age. The mice in these groups were monitored for the appearance of clinical signs of diabetes and were killed at the occurrence of the disease. Finally, we evaluated the effect of VSL\#3 when administered at di- 

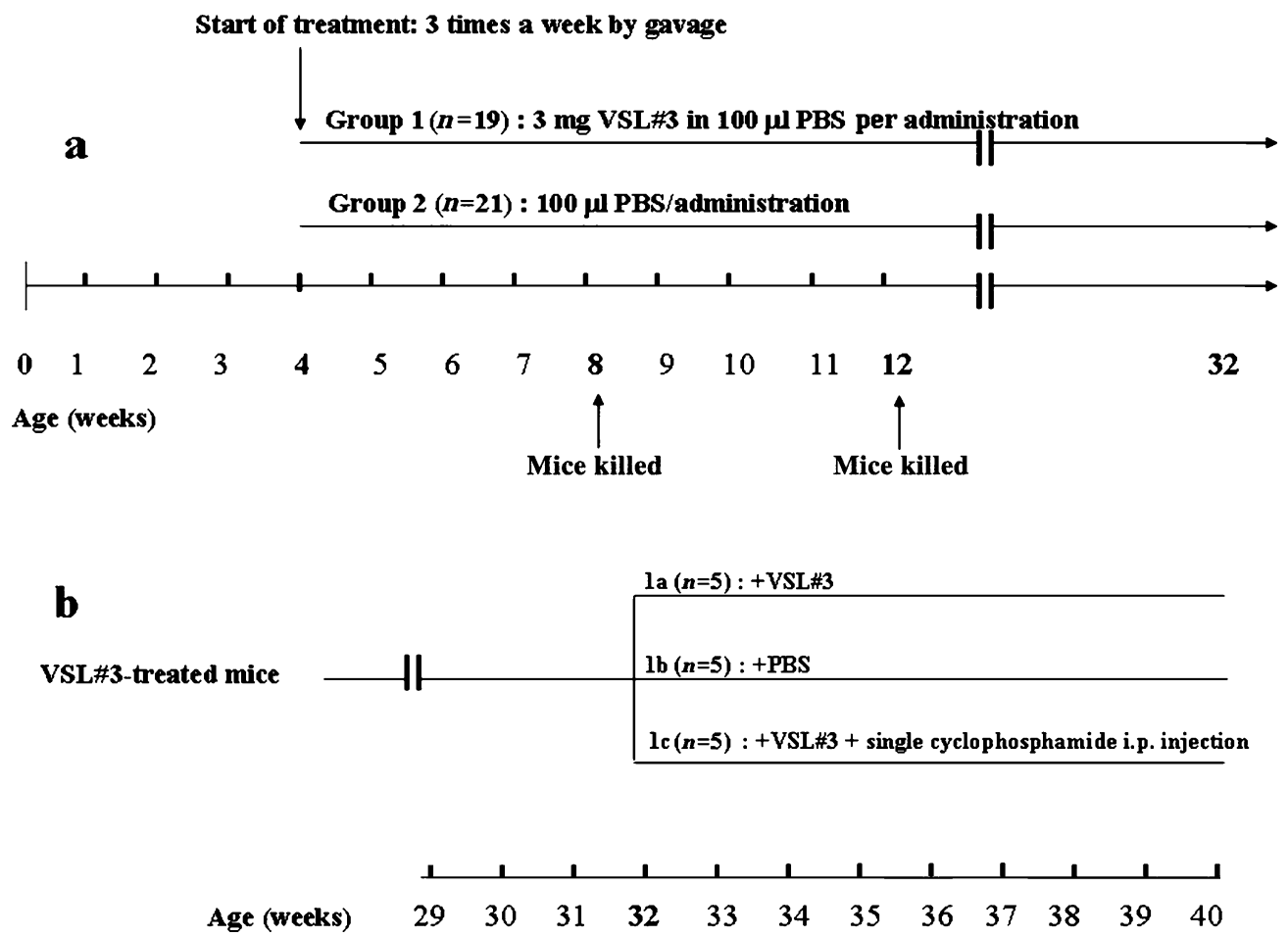

Fig. 1 Experimental design for the evaluation of the effect of VSL\#3 administration on the onset of diabetes in female NOD mice. a Female NOD mice were randomly divided into two groups: group 1, VSL\#3-treated group $(n=19)$; and group 2, PBS-treated group $(n=21)$. In both groups, treatment was started at 4 weeks of age. VSL\#3 (3 mg/mouse per administration, re-suspended in $100 \mu \mathrm{l}$ PBS; group 1) or $100 \mu \mathrm{l}$ PBS alone (group 2) was administered orally by gavage three times per week from 4 to 32 weeks of age. In a separate series of animals, mice treated with VSL\#3 or PBS were killed at 8 and 12 weeks of age (after 4 and 8 weeks of treatment), respectively. b At 32 weeks of age, mice remaining diabetes free in

abetes onset. As such, 16 additional female NOD mice, housed as previously described, were monitored twice a week for the occurrence of diabetes. At diagnosis, NOD mice were treated with VSL\#3 $(n=8)$ or PBS $(n=8)$ following the same protocol as previously described. Blood glucose was checked thereafter twice a week for up to 8 weeks of treatment.

Adoptive transfer In a separate series of animals treated with VSL\#3 or PBS, mice were killed at 12 weeks of age (8 weeks of treatment) to prepare single-cell splenocyte suspensions. Splenocytes were i.v. injected $\left(3 \times 10^{7} /\right.$ mouse $)$ into two separated groups of 775-rad irradiated NOD female mice at 8 weeks of age. The day after, both groups received $3.5 \times 10^{6}$ mononuclear splenocytes isolated from 13- to 15 -week-old female NOD mice with newly onset diabetes. Mice were monitored for the occurrence of diabetes twice a week for up to 11 weeks after transfer.

Diagnosis of diabetes Non-fasting whole blood glucose was measured in all animals twice a week using a glucometer (Medisense; Abbott Laboratories, Abbott Park, IL, USA) and reagent strips. In NOD mice, non-fasting blood the VSL\#3-treated group $1(n=15)$ were divided into three subgroups: subgroup 1a continued VSL\#3 treatment under the same conditions $(n=5)$; subgroup $1 \mathrm{~b}$ stopped VSL\#3 treatment and started PBS administration as for group $2(n=5)$; and subgroup 1c continued VSL\#3 treatment and received a single i.p. cyclophosphamide injection $(n=5)$. The study was stopped at 40 weeks (280 days) of age and all non-diabetic remaining mice from all groups were killed. When a mouse was killed, the spleen, the pancreas and PPs of each mouse were collected for evaluation of insulitis and assessment of cytokine production

glucose ranges from 3 to $8 \mathrm{mmol} / \mathrm{l}(95 \% \mathrm{CI})$. Diabetes was defined as two consecutive readings above $12 \mathrm{mmol} / \mathrm{l}$.

Histology and immunohistochemistry The pancreases from killed mice were removed and divided into two halves. One half was fixed in $10 \%$ buffered formalin for $20 \mathrm{~h}$ and embedded in paraffin. Sections of $4 \mu \mathrm{m}$ were cut $40 \mu \mathrm{m}$ apart throughout the gland and stained with haematoxylineosin (H-E; Merck, Whitehouse Station, NJ, USA) for the evaluation of the insulitis score using the following scale: 0 , intact islet; 1 , peri-insulitis; 2 , moderate insulitis $(<50 \%$ of the islet infiltrated); 3 , severe insulitis ( $\geq 50 \%$ of the islet infiltrated). At least 30 islets per pancreas were analysed by two independent examiners.

The second half of the pancreas was snap-frozen in liquid nitrogen and subsequently used for immunohistochemical studies or for mRNA expression analyses by real-time PCR.

Staining of IL-10 and IFN- $\gamma$ was performed on cryostat acetone-fixed pancreatic sections by incubation for $1 \mathrm{~h}$ with either rat anti-mouse-IL-10 primary monoclonal antibody (Endogen, Woburn, MA, USA; distributed by Tema Ricerca, Bologna, Italy) diluted 1:400 in 3\% BSA-PBS, or 
with rat anti-mouse IFN- $\gamma$ primary monoclonal antibody (Abcam, Cambridge, UK) diluted 1:400 in 3\% BSA-PBS. This step was followed by $1 \mathrm{~h}$ of incubation with peroxidase-conjugated rabbit anti-rat antibody (Sigma-Aldrich, St Louis, MO, USA). The colour was revealed using the 3,3'-diaminobenzidine revelation system (Vector kit; Vector Laboratory, Burlingame, CA, USA).

Insulin staining and histomorphometric analysis Insulin staining was performed on 4- $\mu$ m paraffin-embedded pancreatic sections by incubation for $1 \mathrm{~h}$ with guinea pig anti-porcine insulin primary polyclonal antibody (Dako, Carpinteria, CA, USA) diluted 1:100 in PBS, followed by $1 \mathrm{~h}$ of incubation with peroxidase-conjugated rabbit antiguinea pig secondary antibody (Dako) diluted 1:200 in PBS. The colour was revealed using the 3,3'-diaminobenzidine revelation system (Vector kit). Histomorphometric analysis of insulin-stained pancreatic sections was carried out on two to three 4- $\mu \mathrm{m}$ sections from each animal using an interactive image analyser (IAS 2000; Delta Sistemi, Rome, Italy). The sections were cut at intervals of approximately $40 \mu \mathrm{m}$, and the area of the Langerhans islets occupied by beta cells (cells stained positive for in-

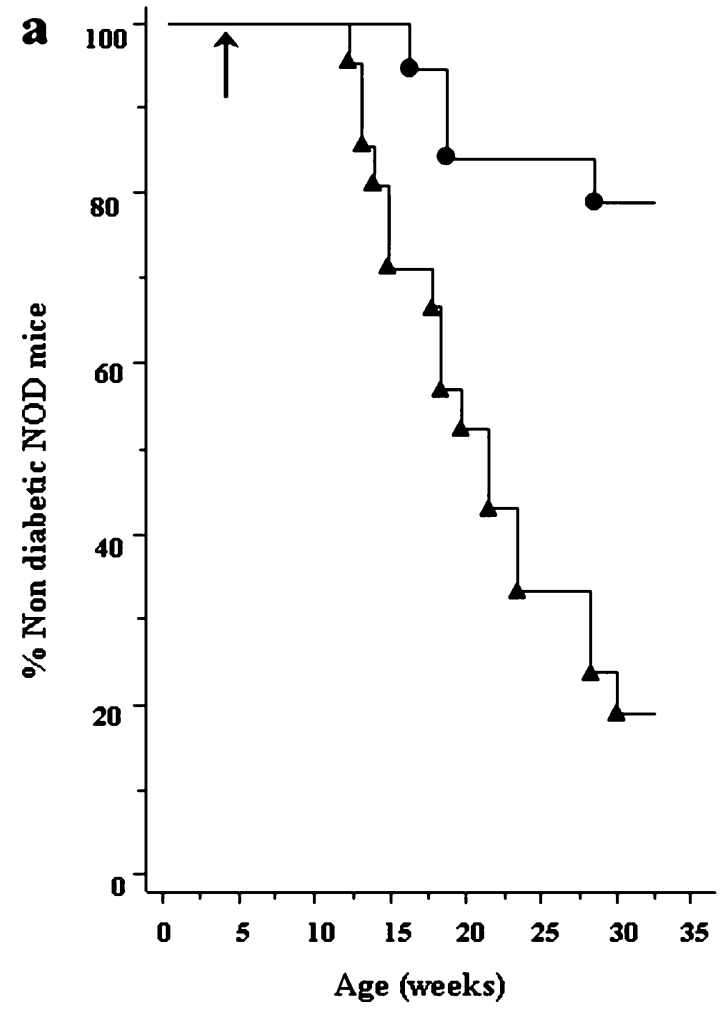

Fig. 2 Delayed onset and reduced incidence of diabetes in NOD mice administered with VSL\#3. a Life-table analysis of NOD mice treated with PBS or VSL\#3 starting from 4 weeks of age (arrow) showing the percentage of non-diabetic NOD mice plotted against age. The analysis shows a delay in the first diagnosis of diabetes at 12 weeks of age in PBS-treated mice (triangles) and at 16 weeks of age in VSL\#3-treated mice (circles). At 32 weeks of age, $81 \%$ $(17 / 21)$ of PBS-treated NOD mice were diabetic, in comparison with $21 \%(4 / 19)$ of mice in the VSL\#3-treated group $(p<0.001$ by sulin) was measured as a percentage ratio of the total area of the same islets.

Cell isolation and cultures Spleens were removed, minced and filtered through sterile 100- $\mu \mathrm{m}$ filters (Falcon; Becton Dickinson, Franklin Lakes, NJ, USA). Cell suspensions were then washed in Hanks' balanced salt solution (HBSS; BioWhittaker Europe, Verviers, Belgium), and erythrocytes were removed by osmotic lysis (ACK lysing buffer; BioWhittaker).

The intestines of the mice were isolated and PPs were carefully excised and incubated at $37^{\circ} \mathrm{C}$ for $15 \mathrm{~min}$ in 5 mmol/1 EDTA-HBSS. After this step, mechanical dissociation of PPs through a nylon mesh grid was performed. The resulting cell suspension was then washed in HBSS and the pellet re-suspended in 30\% Percoll (Sigma-Aldrich) with $1 \mathrm{mmol} / 1$ EDTA, and centrifuged at $400 \mathrm{~g}$ for $25 \mathrm{~min}$ at $20^{\circ} \mathrm{C}$. Mononuclear cells (MNCs) were recovered, washed twice in HBSS, counted and cultured as follows.

Cells were re-suspended at the concentration of $1 \times 10^{6}$ cells/ml in complete medium consisting of RPMI 1640 (BioWhittaker) supplemented with $2 \mathrm{mmol} / \mathrm{l} \mathrm{L}$-glutamine, $25 \mathrm{mmol} / \mathrm{l}$ HEPES buffer (BioWhittaker) and $5 \mu \mathrm{g} / \mathrm{ml}$

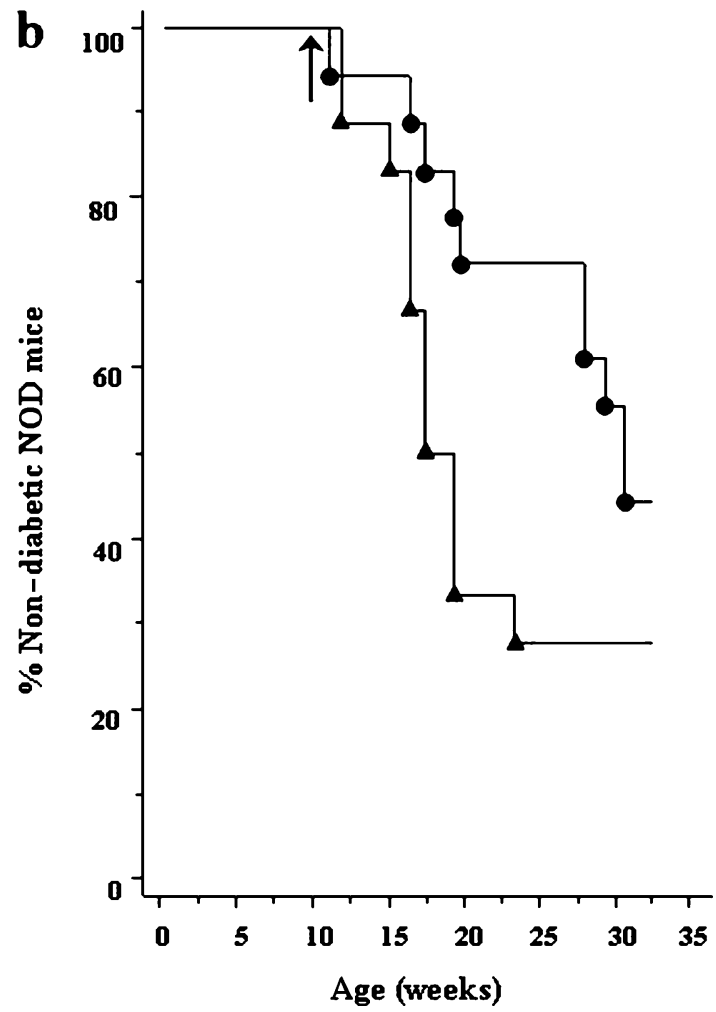

Kaplan-Meier analysis curve with log-rank test). b Life-table analysis of NOD mice treated with PBS (triangles) or VSL\#3 (circles) starting from 10 weeks of age (arrow) showing the percentage of non-diabetic NOD mice plotted against age. The analysis shows a significant reduction in the frequency of diabetes in VSL\#3-treated animals at 190 days of age ( $p=0.028$ by KaplanMeier analysis curve with log-rank test) but not at the end of the study 
gentamicin, $50 \mathrm{U} / \mathrm{ml}$ penicillin and $50 \mu \mathrm{g} / \mathrm{ml}$ streptomycin. Cells were cultured in complete medium plus either $10 \%$ FBS (HyClone Europe, Cramlington, UK) for evaluation of IFN- $\gamma$, IL-4 and IL-10 production, or $1 \% \mathrm{Nu}-$ tridoma SP (Roche Diagnostics, Mannheim, Germany) for evaluation of TGF- $\beta$ production. Cells were cultured in 24-well plates (Costar Corporation, Cambridge, MA, USA), coated or not with anti-CD3 $\in$ antibody (clone 145-2C11; PharMingen, San Diego, CA, USA). Coating was accomplished by pre-exposure of individual wells to $10 \mu \mathrm{g} / \mathrm{ml}$ murine anti-CD $3 \in$ antibody in carbonate buffer $(\mathrm{pH} 9.6)$ for $1 \mathrm{~h}$ at $37^{\circ} \mathrm{C}$. Soluble anti-CD28 antibody $(1 \mu \mathrm{g} / \mathrm{ml}$; clone 37.51; PharMingen) was also added to the coated wells.
After $48 \mathrm{~h}$ of culture under these conditions (or $72 \mathrm{~h}$ for TGF- $\beta$ ), culture supernatants were collected and stored at $-80^{\circ} \mathrm{C}$ until tested.

ELISA Cytokine concentrations in culture supernatants (IL-10, IL-4 and IFN- $\gamma$ ) were measured using commercially available specific ELISA kits (Endogen), while TGF- $\beta$ concentration was measured using the commercially available TGF- $\beta$ quantikine kit (R\&D Systems, Abingdon, UK). Optical densities were measured using a Bio-Rad Novapath ELISA reader (Bio-Rad, Hercules, CA, USA) at a wavelength of $450 \mathrm{~nm}$.

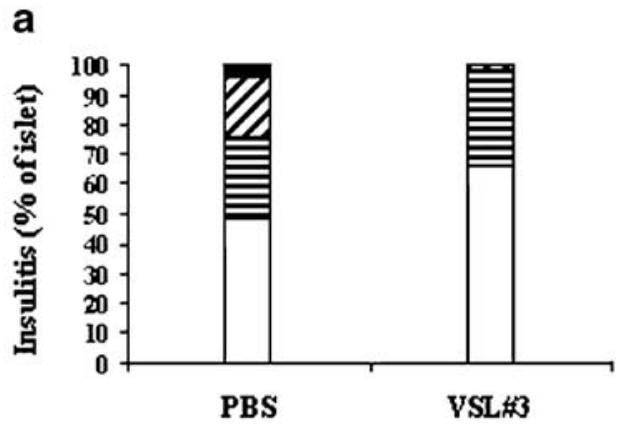

a
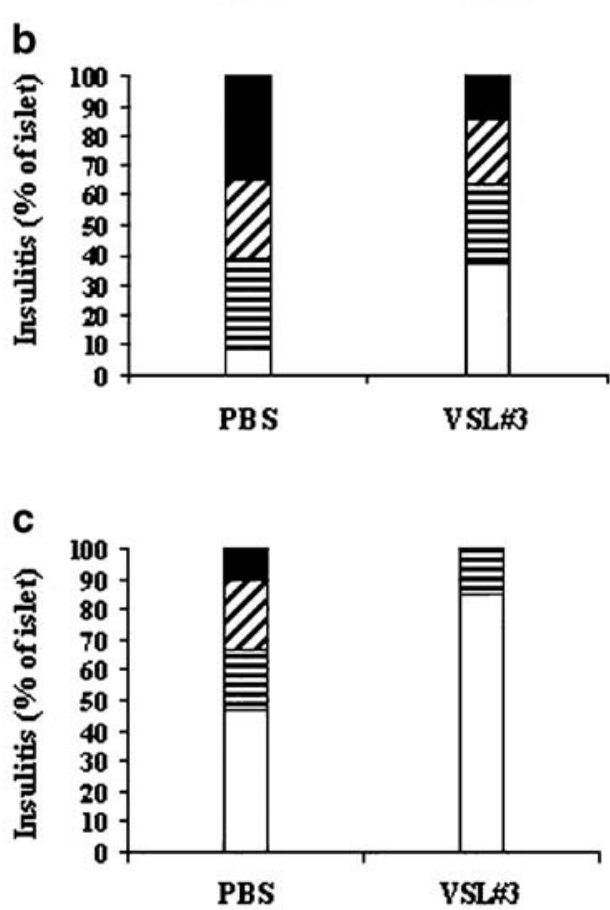

d

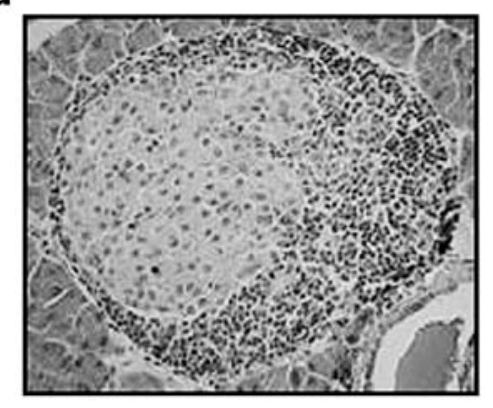

e

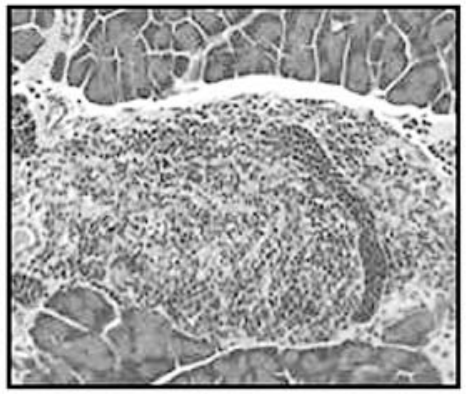

f

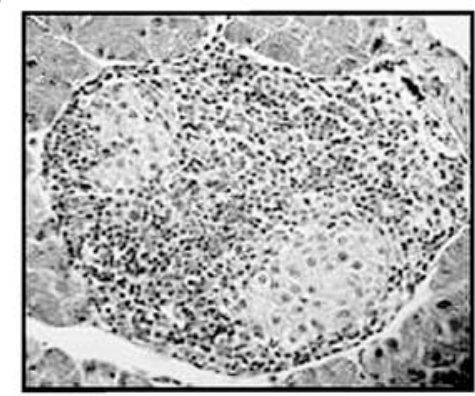

PBS g

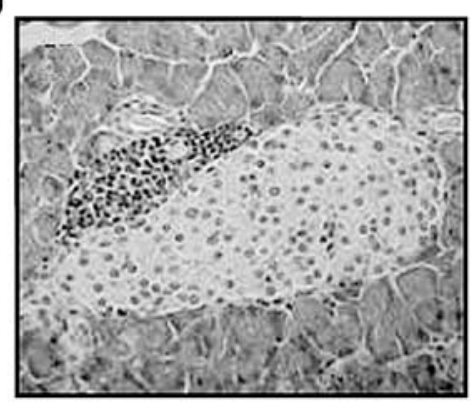

h

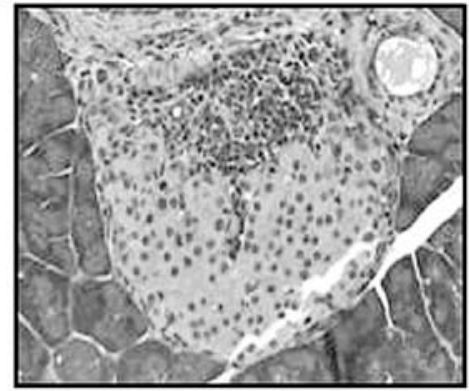

i

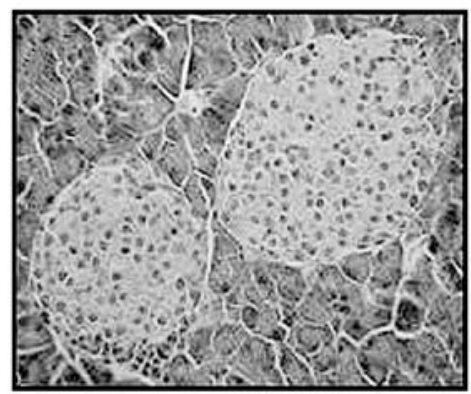

VSL\#3
Fig. 3 Reduced insulitis score in non-diabetic VSL\#3-treated NOD mice vs PBS-treated NOD mice. a-c Insulitis score in non-diabetic NOD mice treated with PBS or VSL\#3 at 8 (a), 12 (b) and 40 (c) weeks of age (4 and 8 weeks of treatment and at the end of the study). In VSL\#3-treated mice, 108, 386 and 105 islets were evaluated at the indicated time points. In PBS-treated mice, 92, 207 and 91 islets were evaluated at the indicated time points. For the evaluation of insulitis score the following scale was used: 0 (white), intact islet; 1 (horizontal lines), peri-insulitis; 2 (oblique lines), moderate insulitis; 3 (black), severe insulitis. $p=0.002$ for VSL\#3 treatment vs PBS treatment at 8 weeks of age; $p<0.001$ for VSL\#3 treatment vs PBS treatment at 12 and 40 weeks of age. d-i Representative microphotographs $(\times 400)$ of histological $\mathrm{H}-\mathrm{E}$-stained paraffin pancreatic sections from PBS-treated $(\mathbf{d}-\mathbf{f})$ or VSL\#3-treated $(\mathbf{g}-\mathbf{i})$ NOD mice at $8(\mathbf{d}, \mathbf{g}), 12(\mathbf{e}, \mathbf{h})$ and $40(\mathbf{f}, \mathbf{i})$ weeks of age 
RNA extraction and real-time PCR Total RNA was extracted from frozen pancreatic tissue using Trizol (GibcoBRL, Grand Island, NY, USA) and cDNA prepared as previously described [26]. Quantitative analysis of mouse IL-10, IFN- $\gamma$ and $\beta$-actin mRNA expression was performed in triplicate by real-time PCR as previously described [27] using TaqMan pre-developed assay reagents (Applied Biosystems, Foster City, CA, USA) and the ABI Prism 7700 sequence detection system (Applied Biosystems). Results were normalised for $\beta$-actin content and expressed as arbitrary units.

Cyclophosphamide treatment Cyclophosphamide (Endoxan-Asta; Asta Medica, Frankfurt, Germany) was prepared according to manufacturer's instructions immediately before injection by adding sterile distilled water to lyophilised cyclophosphamide to a final concentration of $20 \mathrm{mg} / \mathrm{ml}$. Mice randomised in the cyclophosphamide treatment group (Fig. 1b, group 1c) received a single i.p. injection $(250 \mathrm{mg} / \mathrm{kg}$ body weight $)$ of the drug. All mice were tested as non-diabetic before treatment and blood glucose was monitored twice a week after treatment.

Statistical analysis Diabetes incidence in the two groups was compared by the Kaplan-Meier analysis curve with a log-rank test. The Mann-Whitney $U$-test was used to compare cytokine production, insulitis score and percentage ratio of cells stained positive for insulin among dif- ferent groups. A $p$ value of less than 0.05 was considered significant.

\section{Results}

VSL\#3 administration delays the onset of and reduces the incidence of diabetes in NOD mice The effect of VSL\#3 on the development of autoimmune diabetes in NOD mice was studied by evaluating the time of onset and the incidence of diabetes.

As shown in Fig. 2a, beginning the treatment at weaning resulted in a delay in the first diagnosis of diabetes in VSL\#3-treated mice (16 weeks of age) as compared with the PBS-treated group (12 weeks of age). In addition, VSL\#3-treated mice showed a significantly lower incidence of diabetes than controls ( $p<0.001$ by Kaplan-Meier analysis). To further characterise the mechanism of VSL\#3induced protection, we evaluated the persistence of protection and the possibility of abrogating the protective effect. To this end, non-diabetic VSL\#3-treated mice were subdivided into three subgroups at 32 weeks of age (Fig. 1b). None of the five mice with suspended VSL\#3 treatment (group 1b), and none of the five mice with continued VSL\#3 treatment (group 1a) developed overt diabetes during a subsequent follow-up period of 8 weeks. In contrast, all five mice treated with a single injection of cyclophosphamide (group 1c) developed overt diabetes within 2 weeks,
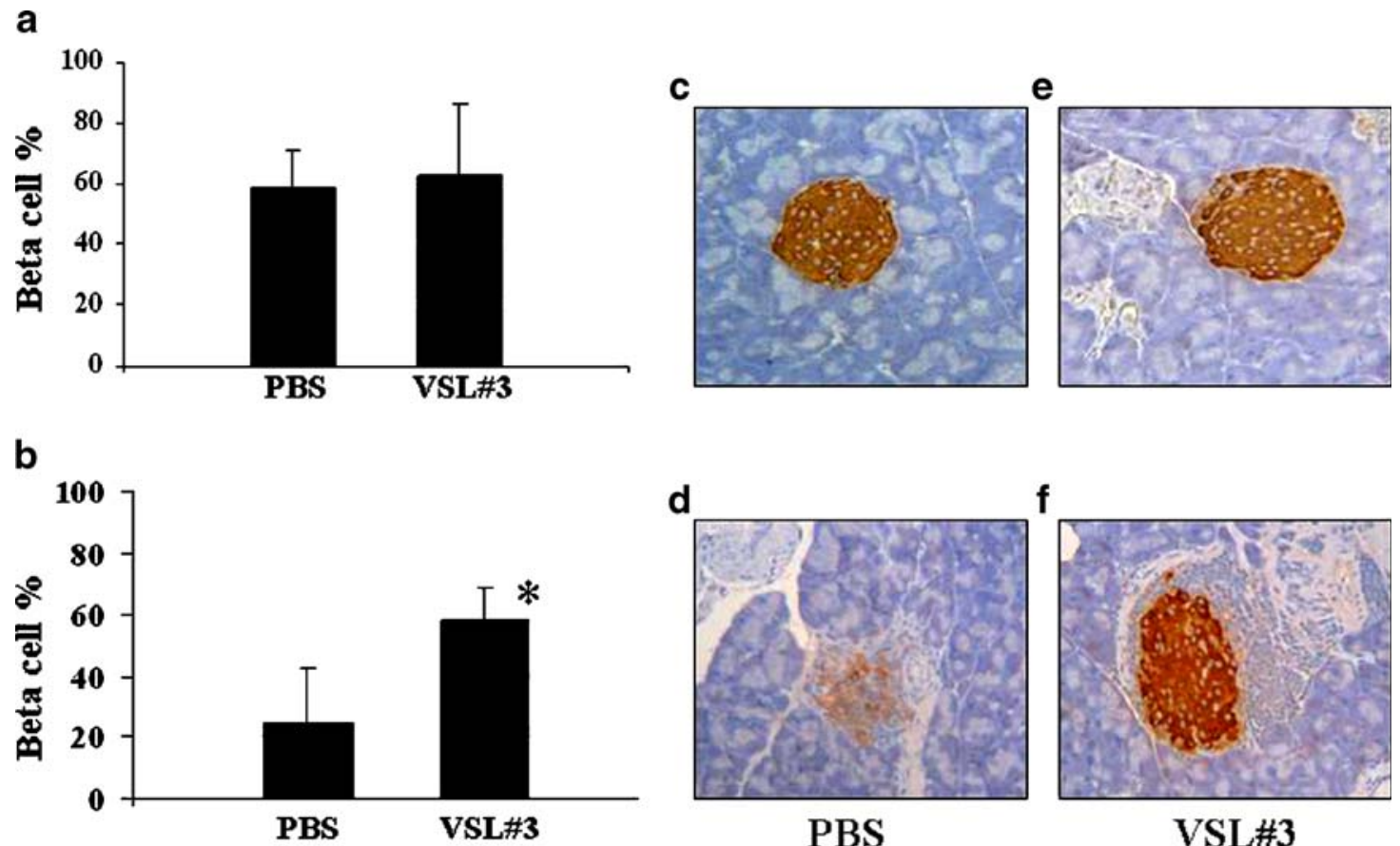

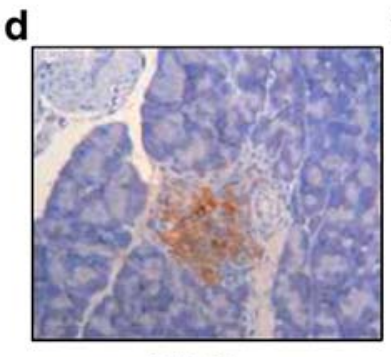

PBS

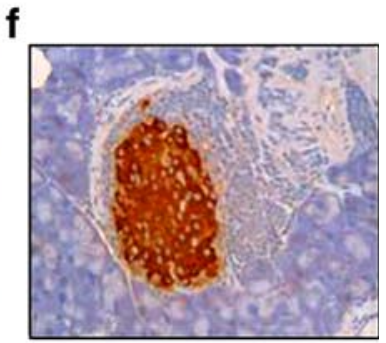

VSL\#3

Fig. 4 Reduced rate of beta cell destruction in non-diabetic VSL\#3treated NOD mice at 12 weeks of age. a, b Histomorphometric analysis of beta cells after insulin staining in pancreatic paraffinembedded sections at 8 (a) and 12 (b) weeks of age. In VSL\#3treated mice, 54 and 72 islets were evaluated at the indicated time points. In PBS-treated mice, 68 and 43 islets were evaluated at the

indicated time points. ${ }^{*} p=0.019$ for VSL\#3-treated vs PBS-treated mice (b). c-f Representative microphotographs $(\times 400)$ of immunoperoxidase insulin staining on pancreatic paraffin-embedded sections from non-diabetic PBS- $(\mathbf{c}, \mathbf{d})$ or VSL\#3- $(\mathbf{e}, \mathbf{f})$ treated NOD mice at $8(\mathbf{c}, \mathbf{e})$ and $12(\mathbf{d}, \mathbf{f})$ weeks of age 
in spite of concomitant VSL\#3 treatment. When VSL\#3 or PBS treatment was started at 10 weeks of age, we did not observe any delay in the first diagnosis of diabetes in animals treated with probiotics (Fig. 2b). At 190 days, VSL\#3-treated mice showed a significantly lower incidence of diabetes than controls $(p=0.028$ by Kaplan-Meier analysis). However, at the end of the study, frequency of diabetes was not significantly lower in VSL\#3-treated mice than in PBS-treated mice (Fig. 2b).

In addition, no effect in terms of reversal of the hyperglycaemic state was observed when VSL\#3 treatment was started at diabetes onset.
VSL\#3-treated mice show reduced insulitis and a decreased rate of beta cell destruction In the group of mice treated from 4 to 32 weeks of age we evaluated the degree of insulitis and the rate of beta cell destruction.

Histological analysis of the pancreas of non-diabetic animals showed the presence of insulitis in both groups of mice, with significant differences in the degree of infiltration between the mice treated with VSL\#3 and those not treated (Fig. 3). In VSL\#3-treated mice, prevalence of different grades of insulitis was always lower than that observed in PBS-treated mice. Moreover, in VSL\#3-treated mice that were switched to PBS treatment at 32 weeks of
Fig. 5 Increased IL-10 production by MNCs isolated from PPs $(\mathbf{a}, \mathbf{c}, \mathbf{e})$ and the spleen $(\mathbf{b}, \mathbf{d}, \mathbf{f})$ of VSL\#3-treated NOD mice. IL-10, IFN- $\gamma$ and IL-4 production by PPs and spleen MNCs from VSL\#3- or PBS-treated animals was evaluated in nondiabetic NOD mice and diabetic NOD mice at diagnosis. Culture supernatants $(48 \mathrm{~h})$ from unstimulated cells (white columns) or anti-CD3/CD28-stimulated cells (black columns) were assayed by specific ELISA for IL-10 (a, b), IFN- $\gamma(\mathbf{c}, \mathbf{d})$ and IL-4 (e, f).

Columns represent mean values obtained from at least five animals per group. Bars represent standard errors. $* p<0.05$ for non-diabetic VSL\#3-treated vs non-diabetic PBS-treated mice and vs diabetic PBS- or VSL\#3treated mice. $N D$ not detectable a

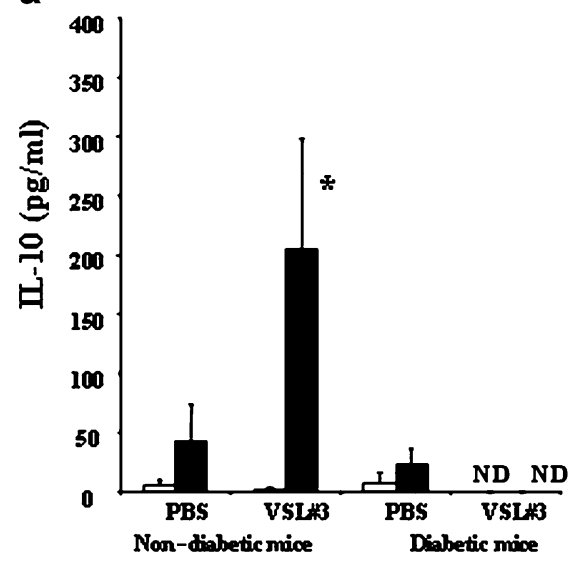

C

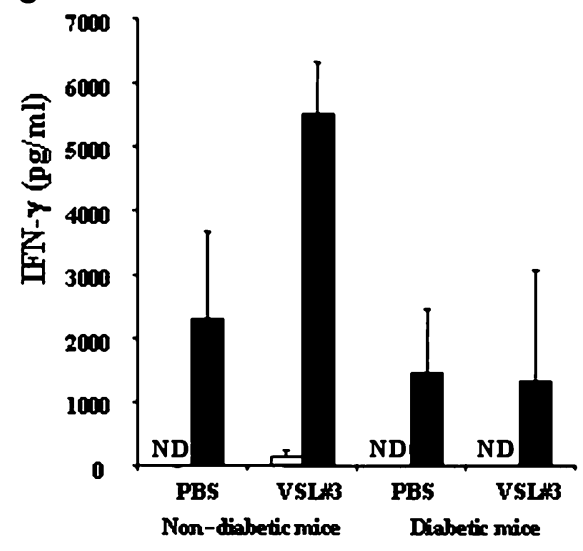

e

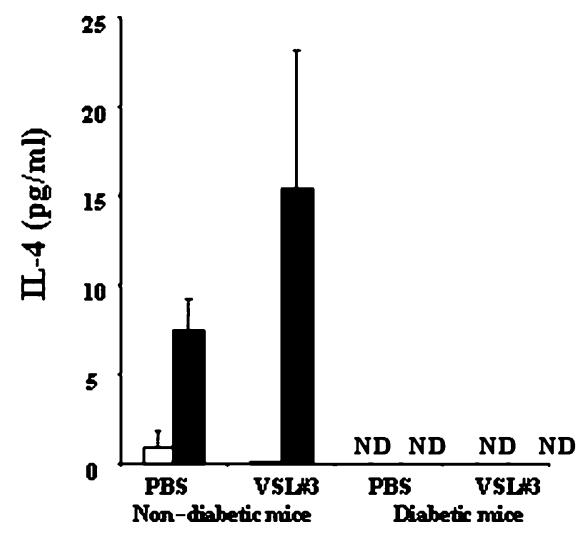

b

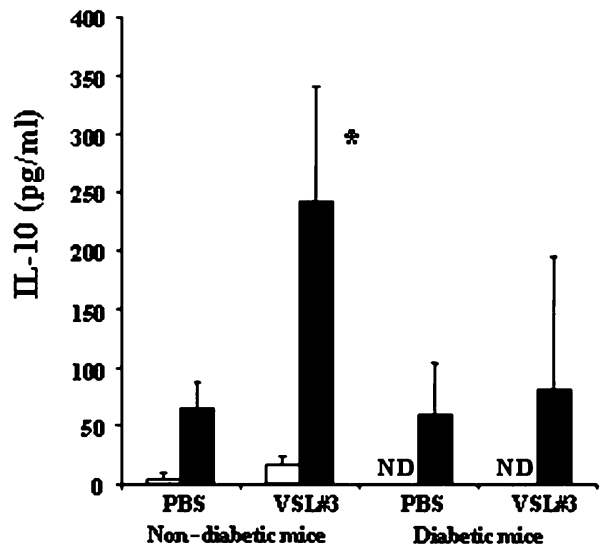

d

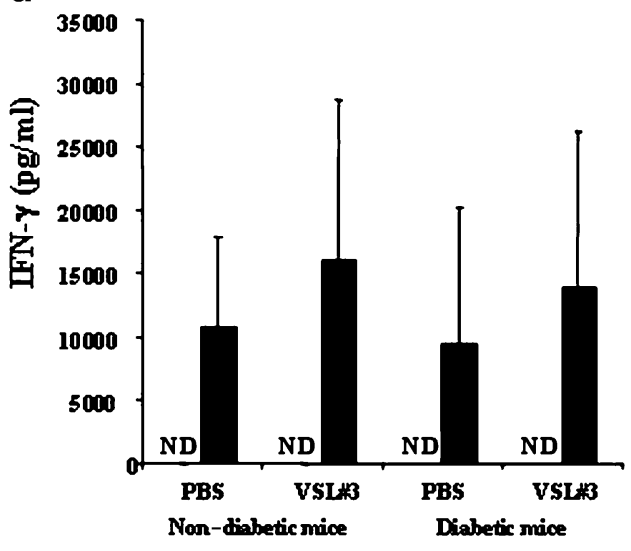

f

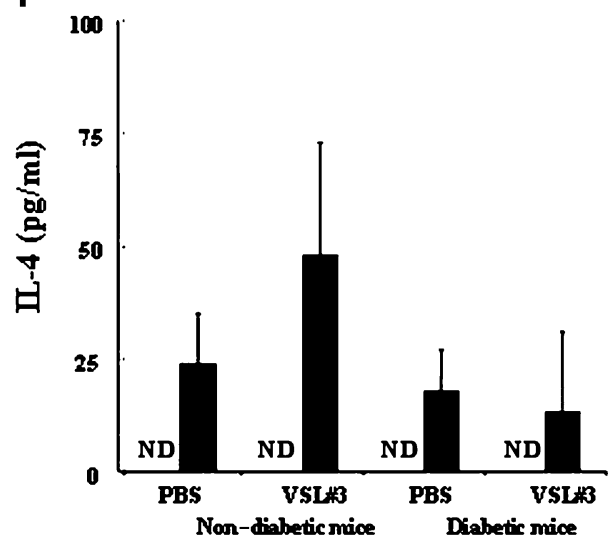


age, histological examination of the pancreas showed the absence of insulitis in $87 \%$ of islets, with $12 \%$ of islets showing only peri-insulitis. Furthermore, at 12 (but not at 8 ) weeks of age, the pancreas of VSL\#3-treated non-diabetic mice showed a reduced rate of beta cell destruction, as evidenced by a minimal loss of insulin-positive cells compared with PBS-treated mice (Fig. 4d, f). As shown in Fig. 4a, b, quantification of islet beta cell content by histomorphometric analysis confirms this observation. In particular, at 12 weeks of age (week 8 of treatment), insulinpositive beta cells represented $57.9 \pm 10.8 \%$ of the islet microscopic surface section in VSL\#3-treated NOD mice, and $24.9 \pm 17.6 \%$ in PBS-treated NOD mice ( $p=0.019$; Fig. $4 b)$.

As expected, all the pancreata removed from the diabetic animals, irrespective of the treatment group, showed a very low number of islets that were severely infiltrated and showed no insulin staining (data not shown).

Protection from diabetes in VSL\#3-treated mice is associated with increased IL-10 production by isolated PPs and spleen MNCs To assess the immunomodulatory role of VSL\#3 administration, cytokine production by MNCs isolated from PPs and the spleen was evaluated in a separate series of mice treated from 4 weeks of age and killed at 8 and 12 weeks of age, and in diabetic mice at the time of diagnosis. Since cytokine production was comparable in each group at the various time points, we pooled the data from the different time points. We show here the average level of each evaluated cytokine. We found a significant increase $(p<0.05)$ in IL-10 production by stim- ulated MNCs isolated from PPs and from the spleen of mice treated with VSL\#3 when compared with PBStreated mice (Fig. 5a, b). This increase was not observable in the diabetic mice of each group (Fig. 5a, b). Slightly higher IFN- $\gamma$ production from MNCs isolated from PPs was detected in VSL\#3-treated mice as compared with control animals (NS). However, the increased IFN- $\gamma$ production was restricted to PP-derived cells from nondiabetic animals (Fig. 5c) and was not detectable in culture supernatants of MNCs isolated from the spleen (Fig. 5d). IL-4 production by PPs and spleen MNCs in VSL\#3treated mice was not statistically different from that observed in PBS-treated mice (Fig. 5e, f). TGF- $\beta$ production was only occasionally detectable and not significantly different between VSL\#3- (spleen: $37.3 \pm 40 \mathrm{pg} / \mathrm{ml}$; PP: $3.9 \pm$ $2.3 \mathrm{pg} / \mathrm{ml}$ ) and PBS- (spleen: $22.9 \pm 40.8 \mathrm{pg} / \mathrm{ml}$; PP: $6.6 \pm$ $5.3 \mathrm{pg} / \mathrm{ml})$ treated mice.

Protection from diabetes in VSL\#3-treated mice is associated with increased IL-10 mRNA expression and with the presence of IL-10-positive infiltrating MNCs in the pancreas To further characterise the VSL\#3-induced protection from diabetes, we quantified and compared by real-time PCR IL-10 and IFN- $\gamma$ mRNA expression in the pancreas of mice treated or not, from 4 weeks of age, with VSL\#3. As shown in Fig. 6a, a statistically significant increase in IL-10 mRNA expression level was observed in the pancreas of VSL\#3-treated mice as compared with that of PBS-treated animals $(p=0.02)$. IFN- $\gamma$ mRNA expression levels were comparable in VSL\#3-treated and PBS-
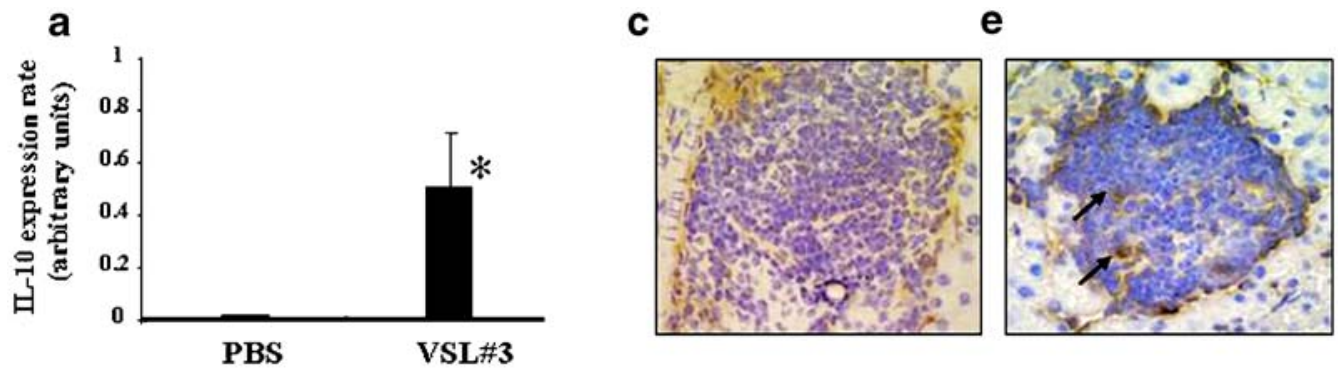

IL-10

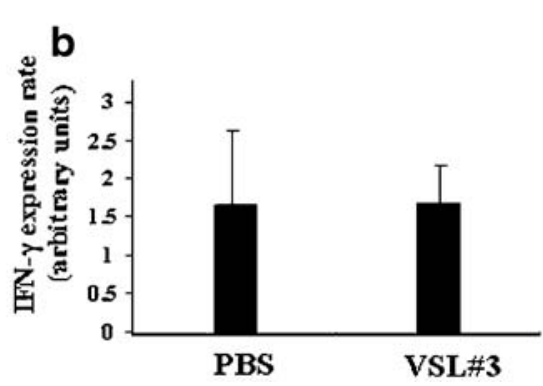

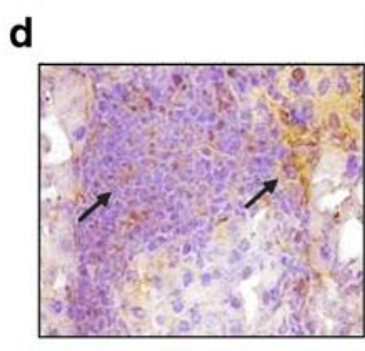

PBS f

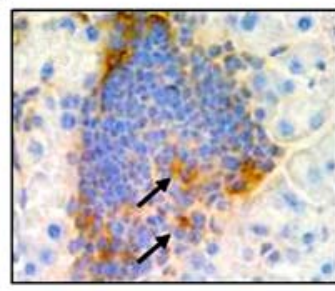

VSL\#3
Fig. 6 Increased IL-10 mRNA expression in the pancreas, and IL10 positivity in the infiltrated islets of VSL\#3-treated NOD mice. a, b Quantitative analysis by real-time PCR of mRNA expression for IL-10 (a) and IFN- $\gamma$ (b) in the pancreas of non-diabetic mice treated with PBS or VSL\#3. Columns represent mean values obtained from four animals per group. Bars represent standard errors. $* p=0.021$ for VSL\#3-treated vS PBS-treated mice (a); $p=0.563$ for VSL\#3- vs PBS-treated mice (b). c-f Representative microphoto- graphs $(\times 400)$ of immunoperoxidase IL-10 (c, e) and IFN- $\gamma(\mathbf{d}, \mathbf{f})$ staining on pancreatic cryostatic sections of PBS- (c, d) and VSL\#3$(\mathbf{e}, \mathbf{f})$ treated NOD mice at 12 weeks of age. IL-10-positive cells were only detected in VSL\#3-treated mice and not in the PBS-treated group. No difference in IFN- $\gamma$ staining was observed between the VSL\#3- and the PBS-treated groups. Arrows point at IL-10-positive and IFN- $\gamma$-positive cells 
Table 1 Occurrence of diabetes after the adoptive transfer of $3 \times 10^{7}$ splenocytes per animal from VSL\#3-treated or PBS-treated mice into irradiated NOD females

\begin{tabular}{llccc}
\hline & Donor cells & $\begin{array}{l}\text { Recipient } \\
\text { mice }(n)\end{array}$ & $\begin{array}{l}\text { Diabetic mice } \\
(5 \text { weeks after transfer })\end{array}$ & $\begin{array}{l}\text { Diabetic mice } \\
(11 \text { weeks after transfer })\end{array}$ \\
\hline Group A & Splenocytes from PBS-treated mice & 5 & 5 & NA \\
Group B & Splenocytes from VSL\#3-treated mice & 5 & 0 & 0 \\
\hline
\end{tabular}

Both groups (A and B) received $3.5 \times 10^{6}$ splenocytes from newly diabetic NOD females (see Materials and methods)

$N A$ not applicable because all animals became diabetic within 5 weeks of transfer

treated mice (Fig. 6b). Finally, we evaluated the presence of IL-10- or IFN- $\gamma$-producing MNCs in islet infiltrates. As shown in Fig. 6, IL-10-positive cells were only detected in islets of VSL\#3-treated mice (Fig. 6e), while IFN- $\gamma$ positive cells were detected in the islets of both VSL\#3and PBS-treated mice (Fig. 6d, f).

Adoptive transfer of splenocytes from VSL\#3-treated mice into naïve mice is associated with protection from diabetes in the recipient mice We tested the ability of splenocytes isolated from VSL\#3-treated mice to transfer protection to irradiated naïve NOD mice when co-transferred with spleen cells isolated from newly diabetic NOD mice (see Materials and methods). As shown in Table 1, 11 weeks after cell transfer we observed full protection from diabetes in mice that received splenocytes from VSL\#3-treated mice. In contrast, the mice that received splenocytes from PBStreated mice all developed diabetes 4 to 5 weeks after cell transfer.

\section{Discussion}

Our study shows that oral administration of VSL\#3 can delay the onset of, and reduce the incidence of, autoimmune diabetes in NOD mice. In the VSL\#3-treated group, diabetes prevention was associated with less destructive islet-specific autoimmunity and significantly increased production of IL-10 by isolated PPs and spleen MNCs. Moreover, in VSL\#3-treated mice we were able to show the presence, in pancreatic islet infiltrates, of an increased level of IL-10 mRNA expression and an increased number of IL10-positive MNCs. It has been observed that mucosal addressin cell adhesion molecule (MAdCAM-1) becomes expressed on islet vessels of NOD mice in the early phase of lymphocyte accumulation in islets, and that it preferentially mediates the homing of $\beta 7$-integrin ${ }^{\text {high }}$, L-selectin-positive mucosal lymphocytes [28-31]. Therefore, MAdCAM-1 islet expression could favour early accumulation of mucosal-associated lymphocytes in pancreatic islets. In addition, $\alpha 4 \beta 7$-integrin-positive, GAD-specific, circulating lymphocytes have been detected in type 1 diabetic patients [32]. Both of these observations suggest that GALT may play a critical role in favouring islet-specific autoimmunity in diabetes-prone individuals, even in humans. Our data show that oral VSL\#3 administration in NOD mice induces IL-10-producing cells in GALT. This finding, together with the observation of IL-10-producing lymphocytes in the spleen and in the islet infiltrates, suggests that VSL\#3-induced IL-10-producing lymphocytes may recirculate from GALT and home to the pancreatic islet where they downmodulate destructive insulitis and preserve beta cells.

Previous studies in NOD mice show that IL-10 administration [33] and adeno-associated virus vector-mediated IL-10 gene delivery prevent the development of autoimmune diabetes [34-36]. In addition, low incidence of diabetes in BDC2.5/NOD transgenic mice has been shown to be caused by T-cell regulation involving endogenous IL-10 [37]. Moreover, it has also been shown that IL-10 has a protective effect on the function and survival of isolated human islets exposed to Th1 inflammatory cytokines [26].

IL-10 is generally considered to be an anti-inflammatory cytokine that acts mostly on antigen-presenting cells by inhibiting antigen presentation and inflammatory cytokine production [38]. It has recently been shown that repeated antigen stimulation in the presence of high levels of this cytokine leads to the generation of regulatory T-cells that produce IL-10 and TGF- $\beta$ [39]. These cells can inhibit experimental colitis and allograft rejection [40-42].

In addition, recent in vivo studies suggest that IL-10 production and regulatory $\mathrm{T}$-cells participate in the process of immune tolerance towards intestinal resident flora [43, 44]. In previous studies, the administration of different lactobacilli resulted in the modulation of local and systemic immune responses in humans and animal models $[19,23,45,46]$. This effect is thought to be accomplished through the occurrence of several different biological events [18, 47-49]. In particular, probiotic-soluble products have been shown to influence epithelial ubiquitination by inhibiting the production of inflammatory cytokines $[18,47,48]$. Moreover, probiotics are able to modulate in vitro expression of cytokines and surface maturation markers in murine dendritic cells [50]. However, different species of lactobacilli induce very different dendritic cell activation patterns, and, furthermore, one bacterial species may be able to inhibit the biological activities of other species in the genus. In particular, while the ability to induce IL-12 production is linked to a number of species, all the species tested were able to induce IL-10 production when used at high concentrations [50]. VSL\#3 contains, in addition to bifidobacteria, a combination of several species of lactobacilli, in different proportions but at very high concentrations. It has been shown that VSL\#3 administration at a high dose can maintain antibiotic-induced remission in patients with pouchitis [17] by increasing local production of IL-10 [23]. 
Our study also suggests that the protection from autoimmune diabetes by VSL\#3 oral administration is dominant and is achieved mostly through the induction of regulatory cells. In fact, we were able to prevent diabetes in mice receiving diabetogenic lymphocytes by transferring splenocytes from VSL\#3-treated mice. In addition, cyclophosphamide administration at 32 weeks of age promptly resulted in the development of overt diabetes in all the mice treated. As cyclophosphamide is thought to delete regulatory T-cells [51], our experiments suggest that immunocompetent diabetogenic cells are indeed still present in VSL\#3-treated mice, but they are actively regulated by the regulatory cells induced by probiotic treatment. Active regulation is effective in preventing complete islet destruction and the onset of clinical signs of diabetes when VSL\#3 treatment is started early in the disease process, before the appearance of histological signs of insulitis, but not when it is started when insulitis has already occurred or when clinical diabetes is overt. Stimulation of GALT at the time of weaning may be critical in the natural history of anti-islet autoimmunity in diabetes-prone individuals.

In conclusion, our study provides evidence that oral VSL\#3 treatment, started at weaning in diabetes-prone NOD mice, induces a change in the cytokine secretion pattern by GALT which is associated with a qualitative modification of the islet infiltrates, the down-regulation of islet-specific destructive autoimmunity and, eventually, diabetes prevention. Given the absence of side-effects in VSL\#3 treatment in NOD mice in our study and the demonstrated safety of the use of this compound in humans [17, 52-54], our results provide a sound rationale for future clinical trials of the primary prevention of type 1 diabetes by oral VSL\#3 administration.

Duality of interest. The authors declare that no duality of interest exists. C. De Simone is a shareholder of VSL Pharma. No funding source had any role in the study design, collection or analysis, in data interpretation, or in the writing of the report.

Acknowledgements This study was supported by the Italian Ministry of Health (research project 'Inflammatory bowel disease and autoimmune disease; mucosal immune regulation in the pathogenesis and prevention' art 12 del D.L.gs 502/1992), the Italian Ministry of Research (grant number 2001-063815), the Promoter Foundation ONLUS, and Consorzio Italiano Biotecnologie (CIB).

F. Calcinaro and S. Dionisi contributed equally to this study. A. Falorni, M. Boirivant and F. Dotta share senior authorship.

\section{References}

1. Notkins AL, Lernmark A (2001) Autoimmune type 1 diabetes: resolved and unresolved issues. J Clin Invest 108:1247-1252

2. Devendra D, Liu E, Eisenbarth GS (2004) Type 1 diabetes: recent developments. BMJ 328:750-754

3. Todd JA, Wicker LS (2001) Genetic protection from the inflammatory disease type 1 diabetes in humans and animal models. Immunity 15:387-395

4. Adorini L, Gregori S, Harrison LC (2002) Understanding autoimmune diabetes: insights from mouse models. Trends Mol Med 8:31-38
5. Vaarala $\mathrm{O}$ (2002) The gut immune system and type 1 diabetes. Ann N Y Acad Sci 258:39-46

6. Holmes GKT (2001) Celiac disease and type 1 diabetes mellitus - the case for screening. Diabet Med 18:169-177

7. Ziegler AG, Schmid S, Huber D, Hummel M, Bonifacio E (2003) Early infant feeding and risk of developing type 1 diabetes-associated autoantibodies. JAMA 290:1721-1728

8. Norris JM, Barriga K, Klingensmith G et al (2003) Timing of initial cereal exposure in infancy and risk of islet autoimmunity. JAMA 290:1713-1720

9. Akerblom HK, Vaarala O, Hyoty H, Ilonen J, Knip M (2002) Environmental factors in the etiology of type 1 diabetes. Am J Med Genet 115:18-29

10. Jaakkola I, Jalkanen S, Hänninen A (2003) Diabetogenic T cells are primed both in pancreatic and gut-associated lymph nodes in NOD mice. Eur J Immunol 33:3255-3264

11. Scott FW, Cloutier HE, Kleemann R et al (1997) Potential mechanisms by which certain foods promote or inhibit the development of spontaneous diabetes in BB rats: dose, timing, early effect on islet area, and switch in infiltrate from Th1 to Th2 cells. Diabetes 46:589-598

12. Haavenar R, Ten Brink B, Huis In 't Veld JHJ (1992) Selection of strains for probiotics use. In: Fuller R (ed) Probiotics, the scientific basis. Chapman \& Hall, London, pp 209-224

13. Gorbach SL, Chang TW, Goldin B (1987) Successful treatment of relapsing Clostridium difficile colitis with lactobacillus GG. Lancet 2:1519

14. Isolauri E, Juntunen M, Rautanen T, Sillanaukee P, Koivula T (1991) A human lactobacillus strain (Lactobacillus casei $\mathrm{sp}$ strain GG) promotes recovery from acute diarrhea in children. Pediatrics 88:90-97

15. Oksanen PJ, Salminen S, Saxelin M et al (1990) Prevention of travellers' diarrhoea by lactobacillus GG. Ann Med 22:53-56

16. Hilton E, Kolakowski P, Singer C, Smith M (1997) Efficacy of lactobacillus GG as a diarrheal preventive in travelers. Travel Med 4:41-43

17. Gionchetti P, Rizzello F, Venturi A et al (2000) Oral bacteriotherapy as maintenance treatment in patients with chronic pouchitis: a double-blind, placebo-controlled trial. Gastroenterology 119:305-309

18. Madsen K, Cornish A, Soper P et al (2001) Probiotic bacteria enhance murine and human intestinal epithelial barrier function. Gastroenterology 121:580-591

19. Schultz M, Veltkamp C, Dieleman LA et al (2002) Lactobacillus plantarum $299 \mathrm{~V}$ in the treatment and prevention of spontaneous colitis in interleukin-10-deficient mice. Inflamm Bowel Dis 8:71-80

20. Ghosh S, van Heel D, Playford RJ (2004) Probiotics in inflammatory bowel disease: is it all gut flora modulation? Gut $53: 620-622$

21. Chauviere G, Coconnier MH, Kerneis S, Fourniat J, Servin AL (1992) Adhesion of human Lactobacillus acidophilus strain LB to human enterocyte-like caco-2 cells. J Gen Microbiol 138: $1689-1696$

22. Cunningham-Rundles S, Ahrne S, Bengmark S et al (2000) Probiotics and immune response. Am J Gastroenterol 95:S22S25

23. Ulisse S, Gionchetti P, D'Alo S et al (2001) Expression of cytokines, inducible nitric oxide synthase, and matrix metalloproteinases in pouchitis: effects of probiotic treatment. Am J Gastroenterol 96:2691-2699

24. Miettinen M, Vuopio-Varkila J, Varkila K (1996) Production of human tumor necrosis factor alpha, interleukin-6, and interleukin-10 is induced by lactic acid bacteria. Infect Immun 64:5403-5405

25. Matsuzaki T, Nagata Y, Kado S et al (1997) Prevention of onset in an insulin-dependent diabetes mellitus model, NOD mice, by oral feeding of Lactobacillus casei. APMIS 105:643-649

26. Marselli L, Dotta F, Piro S et al (2001) Th2 cytokines have a partial, direct protective effect on the function and survival of isolated human islets exposed to combined proinflammatory and Th1 cytokines. J Clin Endocrinol Metab 86:4974-4978 
27. Wang T, Brown MJ (1999) mRNA quantification by real time Taqman polymerase chain reaction: validation and comparison with RNase protection. Anal Biochem 269:198-201

28. Hanninen A, Taylor C, Streeter PR et al (1993) Vascular addressins are induced on islet vessels during insulitis in nonobese diabetic mice and are involved in lymphoid cell binding to islet endothelium. J Clin Invest 92:2509-2515

29. Yang XD, Michie SA, Tisch R, Karin N, Steinman L, McDevitt HO (1994) A predominant role of integrin alpha 4 in the spontaneous development of autoimmune diabetes in nonobese diabetic mice. Proc Natl Acad Sci U S A 91:12604-12608

30. Hänninen A, Salmo M, Simell O, Jalkanen S (1996) Mucosaassociated ( $\beta 7$-integrin ${ }^{\text {high }}$ ) lymphocytes accumulate early in the pancreas of NOD mice and show aberrant recirculation behavior. Diabetes 45:1173-1180

31. Kommajosyula S, Reddy S, Nitschke K, Kanwar JR, Karanam M, Krissansen GW (2001) Leukocytes infiltrating the pancreatic islet of nonobese diabetic mice are transformed into inactive exiles by combinational anti-cell adhesion therapy. $\mathrm{J}$ Leukoc Biol 70:510-517

32. Paronen J, Klemetti P, Kantele JM et al (1997) Glutamate decarboxylase-reactive peripheral blood lymphocytes from patients with IDDM express gut-specific homing receptor $\alpha 4 \beta 7$ integrin. Diabetes 46:583-588

33. Pennline KJ, Roque-Gaffney E, Monahan M (1994) Recombinant human IL-10 prevents the onset of diabetes in the nonobese diabetic mouse. Clin Immunol Immunopathol 71:169-175

34. Nitta Y, Tashiro F, Tokui M et al (1998) Systemic delivery of interleukin 10 by intramuscular injection of expression plasmid DNA prevents autoimmune diabetes in nonobese diabetic mice. Hum Gene Ther 9:1701-1707

35. Goudy K, Song S, Wasserfall C et al (2001) Adeno-associated virus vector-mediated IL-10 gene delivery prevents type 1 diabetes in NOD mice. Proc Natl Acad Sci U S A 98:1391313918

36. Yang Z, Chen M, Wu R et al (2002) Suppression of autoimmune diabetes by viral IL-10 gene transfer. J Immunol 168 : 6479-6485

37. Phillips JM, Parish NM, Drage M, Cooke A (2001) Cutting edge: interactions through the IL-10 receptor regulate autoimmune diabetes. J Immunol 167:6087-6091

38. Moore KW, de Waal Malefyt R, Coffman RL, O'Garra A (2001) Interleukin-10 and the interleukin-10 receptor. Annu Rev Immunol 19:683-765

39. Groux H, O'Garra A, Bigler M et al (1997) A CD4+ T-cell subset inhibits antigen-specific T-cell responses and prevents colitis. Nature 389:737-742
40. Singh B, Read S, Asseman C et al (2001) Control of intestinal inflammation by regulatory T cells. Immunol Rev 182:190-200

41. Fuss IJ, Boirivant M, Lacy B, Strober W (2002) The interrelated roles of TGF- $\beta$ and IL-10 in the regulation of experimental colitis. J Immunol 168:900-908

42. Roncarolo MG, Bacchetta R, Bordignon C, Narula S, Levings MK (2001) Type 1 T regulatory cells. Immunol Rev 182:68-79

43. Cong Y, Weaver CT, Lazenby A, Elson CO (2002) Bacterialreactive $\mathrm{T}$ regulatory cells inhibit pathogenic immune responses to the enteric flora. J Immunol 169:6112-6119

44. Kullberg MC, Jankovic D, Gorelick PL et al (2002) Bacteriatriggered CD4(+) T regulatory cells suppress Helicobacter hepaticus-induced colitis. J Exp Med 196:505-515

45. Madsen KL, Doyle JS, Jewell LD, Tavernini MM, Fedorak RN (1999) Lactobacillus species prevents colitis in interleukin 10 gene-deficient mice. Gastroenterology 116:1107-1114

46. Vaarala O (2003) Immunological effects of probiotics with special reference to lactobacilli. Clin Exp Allergy 33:1634-1640

47. Neish AS, Gewirtz AT, Zeng H et al (2000) Prokaryotic regulation of epithelial responses by inhibition of $\mathrm{IkB}-\alpha$ ubiquitination. Science 289:1560-1563

48. Petrof EO, Kojima K, Ropeleski MJ et al (2004) Probiotics inhibit nuclear factor-kB and induce heat shock proteins in colonic epithelial cells trough proteasome inhibition. Gastroenterology 127:1474-1487

49. Rachmilewitz D, Katakura K, Karmeli F et al (2004) Toll-like receptor 9 signaling mediates the anti-inflammatory effects of probiotics in murine experimental colitis. Gastroenterology 126: $520-528$

50. Christensen HR, Frokiaer H, Pestka JJ (2002) Lactobacilli differentially modulate expression of cytokines and maturation surface markers in murine dendritic cells. J Immunol 168:171178

51. Bach JF (2003) Regulatory $T$ cells under scrutiny. Nat Rev Immunol 3:189-198

52. Gionchetti P, Rizzello F, Helwig U et al (2003) Prophylaxis of pouchitis onset with probiotic therapy: a double-blind, placebocontrolled trial. Gastroenterology 124:1202-1209

53. Kim HJ, Camilleri M, McKinzie S et al (2003) Randomized, controlled trial of a probiotic, VSL\#3, on gut transit and symptoms in diarrhea-predominant irritable bowel syndrome. Aliment Pharmacol Ther 17:895-904

54. Mimura T, Rizzello F, Helwig U et al (2004) Once daily high dose probiotic therapy (VSL\#3) for maintaining remission in recurrent or refractory pouchitis. Gut 53:108-114 